\section{Language, Thought, and Communication}

I shall discuss two apparently conflicting views about our use of natural language. The first view, that language is used primarily in thought, has rarely been given explicit formulation but may be associated with the theories of W. V. Quine and Wilfrid Sellars. The second view, that language is used primarily in communication, has been explicitly put forward by Noam Chomsky, J. A. Fodor, and J. J. Katz, among others, and may also be associated (I think) with the theories of Paul Ziff and Donald Davidson. I shall describe each view and then try to say where I think the truth lies.

1. The view that language is used primarily in thought. This view is not that all or even most thinking or theorizing is in some natural language. We may reasonably suppose that animals think, that children can think before they learn a natural language, and that speakers of a natural language can have thoughts they cannot express in language. The view is rather that anyone who fully learns a natural language can and does sometimes think in that language. More precisely, it is that some of a speaker's so-called propositional attitudes are to be construed as, at bottom, attitudes toward sentences of his language. A speaker of English may believe that the door is open by believing-true the sentence, "The door is open." Another may fear that the door is open by fearing-true "The door is open." A third may think of the door's being open by adopting the appropriate attitude toward "The door is open."

Strictly speaking, sentential attitudes involve sentences conceived under one or another, more or less detailed grammatical analysis. I shall return to this point near the end of this essay. For now, I shall speak loosely of sentential attitudes as attitudes toward sentences.

The view that the primary use of language is in thought has roughly the following implications for the theory of communication. Linguistic AUTHOR'S NOTE: The preparation of this paper was supported in part by grants from NEH and NSF. communication is the communication of thought. The parties involved typically communicate with the language they use in thinking. The words used to communicate a thought are the same as or similar to those one "says to oneself" when one has that thought. Linguistic communication does not typically require any complicated system of coding and decoding. Our usual translation scheme for understanding others is what Quine calls the homophonic one. Words are used to communicate thoughts that would ordinarily be thought in those or similar words. It is true that allowance must sometimes be made for irony and other such devices; but in that case the thought communicated is some simple function of what would be normally communicated by a literal use of those words.

More precisely, linguistic communication typically involves communication of what is sometimes called "propositional content." A speaker says, "The door is shut," "Shut the door," "Is the door shut?" or some such thing. He does so in part to get his hearer to think of the door's being shut. This first view holds that in such a situation, if communication is successful, the hearer will think of the door's being shut by adopting the appropriate sentential attitude. We might say that the hearer attends to the sentence, "The door is shut," where this is a technical sense of "attends to."

Notice that the claim is not that a person can think of the door's being shut only by attending to the sentence, "The door is shut." He might instead attend to an "equivalent" sentence, where the relevant sort of equivalence is that discussed near the end of this paper; he might even attend to a nonlinguistic representation that is part of a system of representation he uses in thinking, as long as the representation is relevantly equivalent to "The door is shut" in English. The claim is rather that normally, when a speaker successfully communicates in English by saying, "The door is shut," etc., the hearer thinks of the door's being shut by attending to the English sentence, "The door is shut." There will normally be a relatively simple grammatical relationship between the sentence the speaker uses to communicate certain "propositional content" and the sentence to which the hearer must attend if communication is to be successful. The "deep structure" of the latter sentence is the same as or a part of the deep structure of the former. Since sentential attitudes involve sentences conceived under grammatical analyses, it is sufficient that the hearer should attend to 


\section{Gilbert Harman}

the sentence uttered conceived under the appropriate analysis. In this sense, linguistic communication does not typically make use of complicated principles of coding and decoding and our usual translation scheme is the homophonic one. The hearer need only hear the sentence uttered as having the appropriate structural description. He does not need to go on to translate the sentence, under that description, into anything else in order to understand it.

Proponents of the view that language is primarily used in thought can point out that, although one might use a natural language as a code, so that one's listeners would have to use complicated principles of decoding in order to understand what has been said, this would not be an ordinary case of linguistic communication. They would also point out that, when a person learns a second language, he may at first have to treat the new language as a code; but hopefully he soon learns to think directly in the second language and to communicate with other speakers of that language in the ordinary way, which does not involve complex coding and decoding or any sort of translation.

Furthermore, proponents can say, when a person thinks out loud, it is not always true that he has to find a linguistic way to express something that exists apart from language. Without language many thoughts and other propositional attitudes would not even be possible. In learning his first natural language, a child does not simply learn a code which he can use in communicating his thoughts to others and in decoding what they say. He acquires a system of representation in which he may express thoughts made possible by that very system. This is obvious when one acquires for the first time the language of a science or of mathematics. The claim is that it is no less true when one learns his first natural language.

That provides a rough sketch of the view that language is used primarily in thought. I shall say more about that view below. Now I want to describe the apparently conflicting theory that communication provides the primary use of language.

2. The view that language is used primarily in communication. J. J. Katz states explicitly a view that is implicit in many things said by other linguists:

Roughly, linguistic communication consists in the production of some external, publicly observable, acoustic phenomenon whose phonetic and syntactic structure encodes a speaker's inner, private thoughts
LANGUAGE, THOUGHT, AND COMMUNICATION

or ideas and the decoding of the phonetic and syntactic structure exhibited in such a physical phenomenon by other speakers in the form of an inner, private experience of the same thoughts or ideas. ${ }^{1}$

Katz takes seriously the notion that linguistic communication ordinarily and typically involves such coding and decoding. He does not agree that typically one thinks in language and that the most usual "code" used in communication is the homophonic one. He does not believe that the words used in communication are usually the same as or similar to those that make up the thought communicated. As a result he sees linguistic communication as a relatively complicated business and he takes the main use of language to be its use in communication:

Natural languages are vehicles for communication in which syntactically structured and acoustically realized objects transmit meaningful messages from one speaker to the other. ... The basic question that can be asked about natural languages is: what are the principles for relating acoustic objects to meaningful messages that make a natural lan guage so important and flexible a form of communication? ${ }^{2}$

I think that in theory Noam Chomsky rejects Katz's view of communication and natural languages. He takes the primary function of language to be its use in the free expression of thought. He speaks approvingly of Humboldt's emphasis on the connection between language and thought, especially the way in which a particular language brings with it a world view that colors perception, thought, and feeling. According to Chomsky's description of Humboldt's view, to have a language is to have a system of concepts

and it is the place of a concept within this system (which may differ somewhat from speaker to speaker) that, in part, determines the way in which the hearer understands a linguistic expression ... [T] he concepts so formed are systematically interrelated in an "inner totality," with varying interconnections and structural relations ... This inner totality, formed by the use of language in thought, conception, and expression of feeling, functions as a conceptual world interposed through the constant activity of the mind between itself and the actual objects, and it is within this system that a word obtains its value . . . Consequently, a language should not be regarded merely, or primarily, as a means of communication ... and the instrumental use of language

${ }^{1}$ J. J. Katz, The Philosophy of Language (New York: Harper and Row, 1966), p. 98.

${ }^{2}$ Ibid. Cf. J. J. Katz, "Recent Issues in Semantic Theory," Foundations of Language, $3(1967): 125$. 


\section{Gilbert Harman}

(its use for achieving concrete aims) is derivative and subsidiary. It is, for Humboldt, typical only of parasitic systems (e.g. . . . the lingua franca along the Mediterranean coast). ${ }^{3}$

Chomsky's approval of Humboldt suggests that he would accept the view that language is used primarily in thought and would reject Katz's remarks about language and communication. But other speculations of Chomsky's seem to make sense only if he does at least unconsciously accept a view like Katz's, only if he does see communication as the central function of language, only if he does think linguistics is primarily concerned with the speaker-hearer rather than the thinker, and only if he does take communication to involve a complicated process of decoding.

Consider the view, held by both Katz and Chomsky, that speakers of a language have (unconscious) knowledge of the grammatical rules of the language. We would not ordinarily say that a typical speaker of English has knowledge of the rules of a transformational grammar of English. We would ordinarily attribute such knowledge to a grammarian if to anyone. It has not been easy to discover why Chomsky and Katz attribute such knowledge to speakers generally. I and others have hypothesized that Chomsky and Katz confuse knowing how to use a language that is described by the grammatical rules with knowing that the grammar is described by those rules. ${ }^{4} \mathrm{I}$ have also suggested that Chomsky may be confusing "knowing that certain sentences are grammatically unacceptable, ambiguous, etc., with knowing the rules of grammar by virtue of which sentences are unacceptable, ambiguous, etc."5 I have also suggested that Chomsky fails "to distinguish principles that account for how a person's mind works from principles a person accepts as true." 6

Although these suggestions may contain part of the truth, they do not account for the tenacity with which Chomsky (for one) holds on to

${ }^{3}$ Noam Chomsky, "Current Issues in Linguistic Theory," in J. A. Fodor and J. J. Katz, eds., The Structure of Language (Englewood Cliffs, N.J.: Prentice-Hall, 1964), pp. 58-59. See also Chomsky's remarks about Humboldt in his book Cartesian Linguistics (New York: Harper and Row, 1966).

"Three authors endorse this suggestion in a single issue of Journal of Philosophy, 64 (1967): N. L. Wilson, "Linguistic Butter and Philosophical Parsnips," pp 55-67; Henry Hiz, "Methodological Aspects of the Theory of Syntax," pp. 67-84; and Gilbert Harman, "Psychological Aspects of the Theory of Syntax," pp. 75-87.

"Harman, "Psychological Aspects of the Theory of Syntax," p. 82.

${ }^{\circ}$ Harman, review of Chomsky's Cartesian Linguistics in Philosophical Review, $72(1968): 234$.
LANGUAGE, THOUGHT, AND COMMUNICATION

the view that speakers have (unconscious) knowledge of the rules of grammar. In a paper presented to the 1968 New York University Institute of Philosophy ${ }^{7}$ Chomsky surveys criticism of his views and denies they are based on the above confusions. He acknowledges that it would be "absurd" to suppose a typical speaker to have knowledge that the language is described by certain rules of grammar and claims he wants to say only that a speaker has knowledge of the rules of grammar. On the other hand, there and elsewhere Chomsky describes the speaker's knowledge of the rules as "a system of beliefs" and as a "theory"; and he says that a child who acquires knowledge of the rules "determines that the structure of his language has the specific characteristics that empirical investigation of language leads us to postulate . . ." 8 Surely it will be interesting to see what has led Chomsky to such a position.

Simple common sense can account for his denial that a typical speaker of a language has unconscious knowledge that the language is described by certain rules of grammar. But it is difficult to say what leads him simultaneously to assert that the speaker has knowledge of the rules, knowledge which consists of a system of beliefs or of a theory that the speaker developed in the course of determining that those rules describe the language. Chomsky denies that he makes the mistakes sug gested above. We can only take him at his word. Therefore we must look elsewhere for an explanation of his view.

I suggest we need look no farther than Katz's book on the philosophy of language. It is easy to see why he attributes to speakers unconscious knowledge of the rules of grammar. He takes linguistic communication to involve complex coding and decoding. Since such communication typically involves novel messages not previously encountered, he thinks speakers and hearers will need to know rules that relate sequences of code to messages. Such rules are provided by transformational generative grammars that define the sound-meaning relationship for the language in question. Therefore he thinks that speakers and hearers must have knowledge of rules that are equivalent to the rules of an adequate transformational generative grammar of the language.

7"Linguistics and Philosophy," in Language and Philosophy, ed. Sidney Hook (New York: New York University Press, 1969), pp. 51-94.

${ }^{8}$ This last remark is from Chomsky's part in a symposium on "Recent Contributions to the Theory of Innate Ideas" (Boston Studies in the Philosophy of Science, vol. 3, p. 86). Most of Chomsky's N.Y.U. paper is devoted to clarifying that earlie paper and responding to remarks in that symposium by Putnam and by Goodman. (The emphasis on that is mine.) 


\section{Gilbert Harman}

To understand the ability of natural languages to serve as instruments for the communication of thoughts and ideas we must understand what it is that permits those who speak them consistently to connect the right sounds with the right meanings.

It is quite clear that, in some sense, one who knows a natural language tacitly knows a system of rules. This is the only assumption by which we can account for a speaker's impressive ability to use language creatively. Fluent speakers both produce and understand sentences that they have never previously encountered, and they can do this for indefinitely many such novel sentences. ${ }^{9}$

Given that fluent speakers are fluent because of their knowledge of the rules of the language and that linguistic communication is a process in which the meaning that a speaker connects with the sounds he utters is the same meaning that the hearer connects with these same sounds, it seems necessary to conclude that speakers of a natural language communicate with each other in their language because each possesses essentially the same system of rules. Communication can take place because a speaker encodes a message using the same linguistic rules that his hearer uses to decode it. This becomes clearer when we think of how we learn a foreign language in the classroom. Our teacher and text present us with a more or less accurate approximation of the rules that any speaker of the foreign language tacitly knows. Our task is to learn them well enough for us to produce utterances that can be decoded by speakers of that foreign language and to understand utterances of those speakers themselves. This sort of example brings out the fact that our competence in a foreign language depends on whether, and to what extent, the rules we have been taught are equivalent to those that speakers of the foreign language acquired naturally. But it also shows that each speaker of the foreign language must use essentially the same system of rules ...

.. Roughly, and somewhat metaphorically, we can say that something of the following sort goes on when successful linguistic communication takes place. The speaker, for reasons that are linguistically irrelevant, chooses some message he wants to convey to his listeners: some thought he wants them to receive or some command he wants to give them or some question he wants to ask. This message is encoded in the form of a phonetic representation of an utterance by means of the system of linguistic rules with which the speaker is equipped. This encoding them becomes a signal to the speaker's articulatory organs, and he vocalizes an utterance of the proper phonetic shape. This is, in turn, picked up by the hearer's auditory organs. The speech sounds that stimulate these organs are then converted into a neural signal from

${ }^{\circ}$ Katz, The Philosophy of Language, p. 100.
LANGUAGE, THOUGHT, AND COMMUNICATION

which a phonetic representation equivalent to the one into which the speaker encoded his message is obtained. This representation is decided into a representation of the same message that the speaker originally chose to convey by the hearer's equivalent system of linguistic rules. Hence, because the hearer employs the same system of rules to decode that the speaker employs to encode, an instance of successful linguistic communication occurs. . . .

... A linguistic description . . . describes the knowledge whose possession permits a fluent speaker to communicate with other speakers of his language $\mathrm{L}$ and whose absence prevents those who only speak an other language from communicating with normal monolingual speakers of $\mathrm{L}$ in their language. ${ }^{10}$

Chomsky says nothing quite as explicit; but a similar view of linguistic communication seems to lie behind his version of the thesis that speakers of a language have unconscious knowledge of the grammatical rules of that language. If Chomsky sees communication as requiring the hearer to decode a linguistic message into the appropriate nonverbal thought, then it would be natural for him to believe that a "speakerhearer" must know the appropriate code, must know the rules for coding and decoding. The speaker has never been explicitly taught the code, so he must have developed a theory about it, a system of beliefs about it, on the basis of his observation of other speaker-hearers. $\mathrm{He}$ must have determined that the rules are whatever they are. Since rules linking sound and meaning are what the grammar provides, the speakerhearer has unconscious knowledge of the rules of grammar.

Some such line of thought is responsible for Chomsky's view of linguistic competence. That he does not go on to say (in fact he explicitly denies) that the speaker has unconscious knowledge that the rules are whatever they are must be chalked up to the sudden intrusion of common sense plus the fact that the above picture of communication is not his explicit view but only his tacit background assumption.

Let me try to document this. In Chomsky's explicit remarks about the relations between thought, language, and communication, he endorses the Humboldtian view which is on the whole an elaboration of part of the first sort of view, which I described at the beginning of this essay. Language is primarily an instrument for the free expression of

${ }^{10}$ Ibid., pp. 102-105. Cf. J. J. Katz, "Mentalism in Linguistics," Language, 40 (1964):124-137; reprinted in Leon A. Jakobovitz and Murray S. Miron, eds. Readings in the Psychology of Language (Englewood Cliffs, N.J.: Prentice-Hall, 1967). 


\section{Gilbert Harman}

thought; the instrumental use of language, e.g., in communication, is secondary and based on its primary use; etc. ${ }^{11}$ In practice, however, Chomsky appears to take a different line: "The central fact to which any significant linguistic theory must address itself is this: a mature speaker can produce a new sentence of his language on the appropriate occasion, and other speakers can understand it immediately, though it is equally new to them." ${ }^{12}$ He begins his book, Aspects of the Theory of Syntax, with the remark, "Linguistic theory is concerned primarily with an ideal speaker-listener . . ."13 Similarly, he begins a recent survey article by saying, "At the crudest level of description, we may say that a language associates sound and meaning in a particular way; to have command of a language is to be able, in principle, to understand what is said and to produce a signal with an intended semantic interpretation." ${ }^{14}$ In these and many similar passages Humboldt seems to have been forgotten. Language is no longer seen primarily as an instrument for the free expression of thought but as an instrument for the communication of thought.

I think that Chomsky must be taking the thought communicated to be nonverbal. Otherwise he would not be so impressed by what he calls the "creativity of language": "The most striking aspect of linguistic competence is what we may call the 'creativity of language', that is, the speaker's ability to produce new sentences, sentences that are immediately understood by other speakers although they bear no physical resemblance to sentences which are 'familiar', ${ }^{15}$ This aspect of linguistic competence will only seem "striking" to someone who does not think that the relevant thoughts are in words and that the relevant principle for interpreting what others say is to use the homophonic system of translation from words said to words thought. It seems to me that Chomsky's explanation of this "striking aspect of linguistic competence" is like Katz's: The speaker knows what the sound-meaning correspondence for the language is, he knows the rules of grammar that specify this correspondence. Chomsky has put his claim this way:

"See above, pp. 273-74 and footnote 3.

${ }^{12}$ Chomsky, "Current Issues in Linguistic Theory," p. 50; my emphasis.

${ }^{13}$ P. 3.

${ }^{14}$ Chomsky, "The Formal Nature of Language," Appendix A to Eric H. Lenne berg, Biological Foundations of Language (New York: Wiley, 1967), p. 397.

${ }_{15}$ Chomsky, Topics in the Theory of Generative Grammar (The Hague: Mouton, $1966)$, p. 11. Cf. Chomsky, "Recent Contributions to the Theory of Innate Ideas," pp. $82-83$.

\section{LANGUAGE, THOUGH', AND COMMUNICATION}

The grammar as a whole can thus be regarded, ultimately, as a device for pairing phonetically represented signals with semantic interpretations .... In performing as a speaker or hearer, [one] puts this [grammar] to use. Thus as a hearer, his problem is to determine the structural description assigned by his grammar to a presented utterance (or, where the sentence is syntactically ambiguous, to determine the correct structural description for this particular token), and using the information in the structural description, to understand the utterance. ${ }^{16}$

It is quite obvious that sentences have an intrinsic meaning determined by linguistic rule and that a person with command of a language has in some way internalized the system of rules that determine both the phonetic shape of the sentence and its intrinsic semantic contentthat he has developed what we will refer to as a specific linguistic competence. ... . [T] he technical term 'competence' refers to the ability of the idealized speaker-hearer to associate sounds and meanings strictly in accordance with the rules of his language. The grammar of a language, as a model for idealized competence, establishes a certain relation between sound and meaning - between phonetic and semantic representations . . . Clearly, in understanding a signal, a hearer brings to bear information about the structure of his language. ${ }^{17}$

Chomsky and Halle put the point this way:

The person who has acquired knowledge of a language has internalized a system of rules that determines sound-meaning connections for indefinitely many sentences. Of course, the person who knows a language perfectly has little or no conscious knowledge of the rules that he uses constantly in speaking or hearing, writing or reading, or internal monologue. It is this system of rules that enables him to produce and interpret sentences that he has never before encountered. ${ }^{18}$

What I have been trying to show is that Chomsky's and Katz's talk about unconscious knowledge of the rules of grammar represents more than a careless use of the words "know" and "knowledge." More is involved than a confusion between knowing-that and knowing-how, between knowing that a sentence is ambiguous and knowing the grammatical rules by virtue of which it is ambiguous, or between principles that account for knowledge of a language and knowledge of those principles. Their talk about unconscious knowledge of the rules of grammar

${ }^{10}$ Chomsky, "Current Issues in Linguistic Theory," P. 52.

${ }^{17}$ Chomsky, "The Formal Nature of Language," pp. 397-399.

${ }^{18}$ Noam Chomsky and Morris Halle, The Sound Pattern of English (New York Harper and Row, 1968), p. 3. Cf. Chomsky, "Recent Contributions to the Theory of Innate Ideas," pp. 83-84. 


\section{Gilbert Harman}

ultimately reflects a basic conception of our use of language and a definite picture of linguistic communication.

Let me note in passing that we can now understand Chomsky's and Katz's otherwise puzzling acceptance of what they call a theory of "innate ideas." They think of the child about to learn a language as faced with a gigantic cryptogram, a code-breaking problem of the toughest sort. They are impressed that children are able to break the code so fast, without any training, all by themselves. Perhaps they think about how long it took a whole group of adults to break the Japanese code. In order to account for a child's performance they infer that he must have had information about the nature of the code ahead of time; and they equate such innate information with what used to be called innate ideas. ${ }^{19}$ In this case too, Chomsky and Katz have not simply misused terms like "empiricism," "rationalism," "innate ideas," etc. That's why complaints about their usage fail to move them. Their talk about innate ideas is ultimately based on their conception of the use of language in communication.

3. Two views of semantics. What I will call a compositional theory of meaning holds that a hearer determines what the meaning of an utterance is on the basis of his knowledge of the meaning of its parts and his knowledge of its syntactic structure. Such a view follows naturally from the picture of communication that takes it to involve complex coding and decoding. On that picture, to understand (the meaning of) a sentence is to know what (nonverbal) thought or thoughts the sentence encodes. Meanings are identified with the relevant thoughts. Hence the view is that to know the meaning of an expression is to know what meaning, i.e., thought, the code associates with that sentence. On this view, a general theory of meaning of a language is given by the principles of the code that defines the sound-meaning correspondence for the language. Because of the unbounded nature of language, these principles would have to be compositional or recursive.

Recall that for transformational linguistics, the rules of coding and decoding are given by the grammar. This has three components, a syntactic component that connects a phonological component with a semantic component. And as Katz describes it, "whereas the phonological

${ }^{18}$ Chomsky, Aspects of the Theory of Syntax, pp. 25-59; The Philosophy of Language, pp. 240-282. See also the papers by Chomsky and responses to them in the works cited in footnotes 7 and 8 above.
LANGUAGE, THOUGHT, AND COMMUNICATION

component provides a phonetic shape for a sentence, the semantic component provides a representation of that message which actual utterances having this phonetic shape convey to speakers of the language in normal speech situations." ${ }^{20}$ Katz adds that

The semantic component . . . must contain rules that provide a meaning for every sentence generated by the syntactic component. . . These rules, therefore, explicate an ability to interpret infinitely many sentences. . . . The hypothesis on which we will base our model of the semantic component is that the process by which a speaker interprets each of the infinitely many sentences is a compositional process in which the meaning of any syntactically compound constituent of a sentence is obtained as a function of the meanings of the parts of the constituent. Hence, for the semantic component to reconstruct the principles underlying the speaker's semantic competence, the rules of the semantic component must simulate the operation of these principles by projecting representations of the meaning of higher level constituents from representations of the meaning of the lower level constituents that comprise them ... .

This means that the semantic component will have two subcomponents: a dictionary that provides a representation of the meaning of each of the words in the language, and a system of projection rules that provide the combinatorial machinery for projecting the semantic representation for all supraword constituents in a sentence from the representations that are given in the dictionary for the meanings of the words in the sentence. ${ }^{21}$

The projection rules of the semantic component for a language characterize the meaning of all syntactically well-formed constituents of two or more words on the basis of what the dictionary specifies about these words. Thus, these rules provide a reconstruction of the process by which a speaker utilizes his knowledge of the dictionary to obtain the meanings of any syntactically compound constituent, including sentences. ${ }^{22}$

Here meanings are to be identified with "readings."

Projection rules operate on underlying phrase markers that are partially interpreted in the sense of having sets of readings assigned only to the lower level elements in them. They combine readings already assigned to constituents to form derived readings for constituents which, as yet, have had no readings assigned to them . . . Each constituent of

${ }^{20} \mathrm{Katz}$, The Philosophy of Language, p. 151.

a Ibid., pp. 152-153. Cf. J. A. Fodor, "Some Remarks on the Philosophy of Language," in F. H. Donell, ed., Aspects of Contemporary American Philosophy (Wurzburg.Wien: Physica-Verlag, 1965), pp. 82-83.

${ }^{2}$ Ibid., pp. 161-162. 


\section{Gilbert Harman}

an underlying phrase marker is thus assigned a set of readings, until the highest constituent, the whole sentence, is reached and assigned a set of readings, too. ${ }^{23}$

It is easy to begin to see what is going on here. This theory would certainly be appropriate as an account of the meaning of expressions in one language, e.g., Russian, given in another language taken to be antecedently understood, e.g., English. In that case one would want some general principles for translating Russian into English. Such principles would enable one to know the meaning of Russian expressions because one already knows (in the ordinary sense of this phrase) the meaning of the corresponding English expressions. Katz tries to make the same trick work in order to give an account of the meaning of sentences in English. In effect he envisions a theory that gives principles for translating from English into Mentalese. He thinks these principles are sufficient because one already knows Mentalese.

Proponents of the view that language is primarily used for thought will raise two objections to Katz's theory of communication. They will argue first that the theory is circular, since (as they maintain) Mentalese is simply English used to think in. Second, they will claim that, even apart from that, Katz's maneuver simply shifts the problem back one step. For what would it be to give an account of meaning for Mentalese? One cannot continue forever to give as one's theory of meaning a way to translate one system of representation into another. At some point a different account is needed. Katz's theory only delays the moment of confrontation.

There are two distinct issues here. The first is the difficult quasiempirical question whether thought is in the relevant sense verbal. I shall postpone discussion of that issue. The second is the methodological question whether a semantic theory may presuppose a theory of the nature of thought. Proponents of the view that language is primarily used for thought take semantics to be part of such a theory of the nature of thought. They argue, as it were, that semantics must be concerned in the first instance with the meaning of thoughts.

Katz seems to assume that no account need be given of the meaning of thoughts, as if Mentalese were intrinsically intelligible. (Cf. Chomsky's remark that "sentences have an intrinsic meaning determined by

${ }^{23}$ Ibid., pp. 164-165.

\section{LANGUAGE, THOUGHT, AND COMMUNICATION}

linguistic rule." ${ }^{24}$ ) That is exactly the sort of view Bloomfield ${ }^{25}$ attacked as "mentalistic." In an influential article, ${ }^{28} \mathrm{Katz}$ attempts to answer Bloomfield but only blurs the issue, since he never considers whether Bloomfield's criticisms of mentalism apply against a theory which assumes that semantics can be unconcerned with the meaning of thoughts because of their supposed intrinsic intelligibility.

Thus, distinguish a theory of the meaning of thoughts from a theory of the meaning of messages. I would argue that a theory of the meaning of messages presupposes a theory of the meaning of thoughts. ${ }^{27}$ The former theory might resemble that proposed by Paul Grice. ${ }^{28}$ According to Grice, the thought meant is the one the speaker intends the hearer to think the speaker has, by virtue of his recognition of the speaker's intention. However that may be, in normal linguistic communication, speakers and hearers rely on a regular association between messages and thoughts. Those philosophers and linguists who think that language is used primarily in communication suppose that this association is between sentences in, e.g., English (conceived under particular structural descriptions) and, as it were, sentences in Mentalese. Those who believe that language is used primarily in thought suppose that the association is a trivial one, since the language used to communicate with is normally the same as that used to think with.

A theory of the meaning of thought is either a theory of meaning for natural languages (as is claimed by those who take language to be used primarily in thought) or a theory of Mentalese (if those philosophers and linguists are right who take natural language to be used primarily in communication). In either case, it must exploit the Humboldtian insight that the meaning of a linguistic expression is derived from its function in thought as determined by its place in one's total conceptual scheme. ${ }^{29}$ One must consider the influence of perception on thought, the role of inference in allowing one to pass from some thoughts to others, and the way thought leads to action. The theory we want will

« Chomsky, "The Formal Nature of Language," p. 397.

${ }^{25}$ Leonard Bloomfield, Language (New York: Holt, 1933), and "Linguistic As pects of Science," International Encyclopedia of Unified Science, vol. 1 (Chicago: University of Chicago Press, 1955).

20 "Mentalism in Linguistics."

${ }^{2 n}$ See my "Three Levels of Meaning," Journal of Philosophy, 65 (1968) :590-602

${ }^{28}$ Paul Grice, "Meaning," Philosophical Review, 66 (1957):377-388; "Utterer's Meaning and Intentions," Philosophical Review, 78 (1969):147-177.

20e above, pp. 273-74 and footnote 3. 


\section{Gilbert Harman}

be like that proposed by Wilfrid Sellars in his paper on "language games." ${ }^{30}$ Sellars identifies the meaning of an expression with its (potential) role in the evidence-inference-action language game of thought. Similar theories have been proposed by various philosophers, e.g., Carnap, Ayer, and Hampshire. ${ }^{31}$ And Quine ${ }^{32}$ has argued that meaning at this level admits of a special sort of indeterminacy.

According to proponents of the view that language is used primarily in thought, transformational semantics, with its compositional theory of meaning, provides neither an account of the meaning of language as used to think with nor an account of the meaning of language as used to communicate with. They claim that it cannot provide a theory of the meaning of thought, since a speaker does not understand the words he uses in thinking by assigning readings to them, and that it cannot provide a theory of the meaning of a message, since it treats a relatively simple problem of interpretation as if it were quite complicated.

4. Composition and communication. Compositional theories of meaning depend on the view that language is used primarily in communication. Thus Davidson argues as follows. He says, first, "we are entitled to consider in advance of empirical study what we shall count as knowing a language, how we shall describe the skill or ability of a person who has learned to speak a language." ${ }^{33} \mathrm{He}$ wants to argue for the condition "that we must be able to specify, in a way that depends effectively and solely on formal considerations, what every sentence means. With the right psychological trappings, our theory should equip us to say, for an arbitrary sentence, what a speaker of the language means by that sentence (or takes it to mean)." 34 That last reference, to what a speaker takes the sentence to mean, sounds suspiciously like Katz's view

${ }^{30}$ Wilfrid Sellars, "Some Reflections on Language Games," in Science, Perception, and Reality (London: Routledge and Kegan Paul, 1963)

s1 E.g., Rudolf Carnap, "Testability and Meaning," Philosophy of Science, 3 (1936) and 4 (1937); "Meaning and Synonymy in Natural Languages," Philosophical Studies, 7 (1955):33-47. A. J. Ayer, Language, Truth, and Logic (1936) reprinted as a Dover paperback; The Foundations of Empirical Knowledge (London: Macmillan, 1940). Stuart Hampshire, Thought and Action (London: Chatto and Windus, 1959).

${ }^{82}$ W. V. Quine, Word and Object (Cambridge, Mass.: M.I.T. Press, 1960).

${ }^{33}$ Donald Davidson, "Theories of Meaning and Learnable Languages," in Y. BarHillel, ed., Logic, Methodology, and Philosophy of Science: Proceedings of the 1964

International Congress (Amsterdam: North-Holland, 1965), p. 387.
${ }^{34}$ Ibid.
LANGUAGE, THOUGHT, AND COMMUNICA'TION

described above, which assumes that to give an account of meaning for some language is to say how a "speaker-hearer" is able to correlate meanings, qua thoughts, with sentences. Our suspicions are confirmed by Davidson's explicit argument for the compositional theory:

These matters appear to be connected in the following informal way with the possibility of learning a language. When we can regard the meaning of each sentence as a function of a finite number of features of the sentence, we have an insight not only into what there is to be learned; we also understand how an infinite aptitude can be encompassed by finite accomplishments. Suppose on the other hand the language lacks this feature; then no matter how many sentences a would-be speaker learns to produce and understand, there will remain others whose meanings are not given by the rules already mastered. It is natural to say such a language is unlearnable. This argument depends, of course, on a number of empirical assumptions: for example, that we do not at some point suddenly acquire an ability to intuit the meanings of sentences on no rule at all; that each new item of vocabulary, or new grammatical rule takes some finite time to be learned; that man is mortal. $^{35}$

This argument makes sense only in the presence of an assumption, which Davidson explicitly acknowledges elsewhere, that "speakers of a language can effectively determine the meaning or meanings of an arbitrary expression (if it has a meaning)," 36 where that is understood to mean that a speaker (hearer) understands a sentence by translating it into its Mentalese counterpart (and where Mentalese is not the language used in communication). If speakers of a language can effectively determine the meaning of messages in ordinary linguistic communication by using the homophonic mapping of verbal message onto verbal thought, the assumption does not support Davidson's argument for a compositional theory of meaning.

In the end Davidson argues for a version of the theory that meaning is given by truth conditions. ${ }^{37}$ That is no real improvement over Katz's theory, from the point of view of those who take language to be used primarily in thought. According to Katz, a speaker knows the meaning of sentences of his language because he has mastered the complicated rules (of a transformational generative grammar of his language) that correlate sentences with thoughts. According to Davidson, a speaker knows

${ }^{35}$ Ibid., pp. 387-388.

${ }^{36}$ Donald Davidson, "Truth and Meaning," Synthese, 17 (1967):320.

s Ibid., pp. 304-323. 


\section{Gilbert Harman}

the meaning of sentences of his language because he has mastered the complicated rules (of a truth definition for his language) that correlate sentences with truth conditions. Katz's theory is in trouble if the relevant thoughts are verbal. The same difficulty faces Davidson in a slightly different form, if the relevant knowledge of truth conditions will be verbal. Katz would say that the speaker understands the sentence "Snow is white" by virtue of the fact that he has correlated it with the thought that snow is white. Davidson would (presumably) say that the speaker understands that sentence by virtue of the fact that he knows it is true if and only if snow is white. The difficulty in either case is that the speaker needs some way to represent to himself snow's being white. If the relevant speaker uses the words "snow is white" to represent in the relevant way that snow is white, both Katz's and Davidson's theories would be circular. And, if speakers have available a form of Mentalese in which they can represent that snow is white, so that the two theories avoid circularity, there is still the problem of meaning for Mentalese.

The point is that no reason has been given for a compositional theory of meaning for whatever system of representation we think in, be it Mentalese or English. This point has obvious implications for linguistics, and for philosophy too if only of a negative sort. For example, Davidson uses his theory in order to support objections to certain theories about the logical form of belief sentences. ${ }^{38}$ Since his argument for a compositional theory of meaning fails for the language one thinks in, those objections have no force against theories about the logical form of belief sentences used in thinking or theorizing.

Similar remarks apply to the compositional theory of meaning in Paul Ziff's Semantic Analysis. ${ }^{39} \mathrm{He}$ argues that "the semantic analysis of an utterance consists in associating with it some set of conditions [and] that the semantic analysis of a morphological element having meaning in the language consists in associating with it some set of conditions . . ."40 Very roughly speaking, the relevant conditions are those that must obtain if something is to be uttered without deviance from rele-

${ }^{38}$ See Davidson, "Theories of Meaning and Learnable Languages," and reference therein.

${ }^{80}$ Ithaca, N.Y.: Cornell University Press, 1960.

to Paul Ziff, "On Understanding Understanding Utterances," in Fodor and Katz The Structure of Language, and in Ziff, Philosophic Turnings (Ithaca, N.Y.: Cornell University Press, 1966), sec. 3.
LANGUAGE, THOUGHT, AND COMMUNICATION

vant nonsyntactic semantic regularities.

Ziff says, "In formulating the theory presented here [in Semantic Analysis] I have had but one objective in mind, viz. that of determining a method and a means of evaluating and choosing between competing analyses of words and utterances." 41 If "analysis" here means "philosophical analysis," Ziff's enterprise must be counted a success, especially in the light of his careful discussion of the analysis of the word "good" in the final chapter. And since analysis is perhaps a kind of translation or decoding, it may be possible to defend a compositional theory of meaning as a compositional theory of analysis. (One must see that a proposed analysis of a word is adequate for various contexts and is consistent with analyses suggested for other words.)

But Ziff does not give quite that argument for a compositional theory of meaning; and the argument he does give indicates that he wants more from his theory than a way of evaluating philosophical analyses. His own argument seems to assume that a speaker understands sentences by virtue of being able to give analyses or explications of them. In Semantic Analysis the argument goes like this:

In a general form, the principle of composition is absolutely essential to anything that we are prepared to call a natural language, a language that can be spoken and understood in the way any natural language can in fact be spoken or understood.

How is it that one can understand what is said if what is said has not been said before? Any language whatever allows for the utterance of new utterances both by the reiteration of old ones and by the formation of new ones out of combinations of old elements. Hence any natural language whatever allows for the utterance of both novel utterance tokens and novel utterance types. If a new utterance is uttered and if the utterance is not then and there to be given an arbitrary explication, that one is able to understand what is said in or by uttering the utterance must in some way at least be partially owing to one's familiarity with the syntactic structure of the utterance. ${ }^{42}$

In "On Understanding Understanding Utterances" Ziff is more explicit: part of what is involved in understanding an utterance is understanding what conditions are relevantly associated with the utterance. ...

Someone says 'Hippopotami are graceful' and we understand what is said. In some cases we understand what is said without attending to the discourse the utterance has occurred in or without attending to the con-

Semantic Analysis, sec. 201.

Semantic Analysis, sec. 64. 


\section{Gilbert Harman}

text of utterance. How do we do it?

It seems reasonable to suppose that part of what is involved is this: Such an utterance is understood on the basis of its syntactic structure and morphemic constitution.

Assuming that part of what is involved in understanding an utterance is understanding what conditions are relevantly associated with the utterance, this means that we take a certain set of conditions to be associated with such an utterance on the basis of its syntactic structure and morphemic constitution. ${ }^{43}$

To this the same remarks apply as to the theories of Katz and of Davidson. A speaker can understand that certain conditions are associated with an utterance and can take certain conditions to be associated with an utterance only if he has some way to represent to himself that the conditions are associated with the utterance. And even if the speaker uses Mentalese to represent utterance-conditions correlations, the problem of meaning is merely pushed back one step to Mentalese. Ziff fares no better than Katz or Davidson in showing that we need a compositional theory of meaning for the system of representation that we think with. If speakers of English think in English and we rely on that fact in communication, Ziff gives us no reason why we need a compositional theory of meaning for English.

5. Language used in thought. According to those who say that speakers of a natural language also think in that language, there are levels of meaning. A theory of the first level must account for the meaning of an expression as a function of its role in thought. A theory of the second level must account for the meaning of an expression used to communicate a thought. A theory of the second level must presuppose the first, since linguistic communication typically communicates a thought that can be expressed (roughly speaking) in the same words used for communication. Such exploitation is even involved in ironic and other nonliteral remarks, since in such cases the words of the relevant thought will be some simple function of the words in the message.

Compare this view with the one expressed in Katz and Fodor's paper, "The Structure of a Semantic Theory." 44 The theory is put forward as a level-two theory of meaning in communication. In particular it is sup-

43 "On Understanding Understanding Utterances," secs. 3, 4.

"4. J. Katz and J. A. Fodor, "The Structure of a Semantic Theory," Language, 39 (1963):170-210; reprinted in Fodor and Katz, The Structure of Language, and in Jakobovits and Miron, Readings in the Psychology of Language. Page reference is to this latter source.
LANGUAGE, THOUGHT, AND COMMUNICATION

posed to account for "the way that speakers understand sentences." 45 That suggests it is the sort of theory Grice has tried to develop. But the authors go on to describe it as an account of the meaning or meanings a sentence has when taken in isolation from possible settings in actual discourse. In other words their theory is restricted to giving an account of meaning for those cases in which the message communicates a thought that (on the other view) can be expressed in (roughly) the same words as those in which the message is expressed. They argue that another theory would have to account for the interpretation or interpretations assigned when a sentence occurs in a particular setting. Furthermore they argue that the latter theory must presuppose the one they present. Thus they come close to the other view's distinction between levels one and two, and in a way they attempt to provide a theory of level one. Or rather, Katz and Fodor see the need for three theories, where on the other view only two are needed. First, there is what we have been calling a theory of the meaning of thought, an account of meaning for whatever system of representation one uses to think with. Katz and Fodor say nothing about this theory, perhaps because they take thoughts to be intrinsically intelligible. On the other hand the other view takes this theory to be the most important part of the theory of meaning. Second, there is the theory that associates sentences (under various structural descriptions) used in communication with meanings they have (in isolation from setting and discourse). This theory associates, e.g., sentences of English (conceived under their structural descriptions) with "readings" in the system of representation used in thinking. Katz and Fodor take this theory to be the central part of the theory of meaning, which amounts to a theory of how sentences in, e.g., English are to be translated into Mentalese. The other view takes this part of the theory to be trivial, on the grounds that speakers of English think in English and can use what amounts to the homophonic scheme of translation. (I shall say more about this in a moment.) Third, there is the theory of the meaning of a message in a particular linguistic and nonlinguistic setting. Both sides argree that this is an important part of a theory of meaning and that it presupposes the other parts.

How are we to decide between a view like Katz and Fodor's, which takes language to be used primarily in communication, and the alterna-

4s Ibid., p. 399. 


\section{Gilbert Harman}

tive, which takes language to be used in thought? I tend to favor the latter view, mainly on grounds of simplicity. But on the other side it might be argued that the former theory is needed to account for all the facts. Katz claims that his and Fodor's (and Postal's ${ }^{46}$ ) semantic theory can explain a great number of different things:

beside requiring a semantic component to predict semantic anomaly and ambiguity, we also require it to predict such other semantic properties and relations as synonymy, paraphrase, antonymy, semantic distinctness, semantic similarity, inclusion of senses, inconsistency, analyticity, contradiction, syntheticity, entailment, possible answer to a question, and so forth. ${ }^{47}$

He may justly complain that we have no right to reject transformational semantic theory unless we have some other method to explain or explain away the phenomena in question. In the remainder of this essay I want to describe and defend one alternative method. In the process I hope to say just what (in my opinion) is and what is not salvageable in the views of Chomsky, Katz, and Fodor discussed above.

I shall be concerned mainly with the level-one theory of meaning, i.e., the theory of the meaning of language used to think in. I shall say something about level two, which is concerned with the meaning of messages, only indirectly and in passing.

What is it for an expression to have a meaning on level one? It is certainly not that the relevant person, the "thinker," can assign it one or more "readings." It is rather that he can use it in thought, i.e., that it has a role in his evidence-inference-action language game. He may be able to use the expression in direct perceptual reports. He must certainly be able to use it in (theoretical and practical) reasoning.

Some reasoning is relatively formal. It depends only on the logical or grammatical form of relevant expressions and is not a function of nonlogical or nongrammatical vocabulary. In order to account for a person's ability to reason formally, it is plausible to suppose that he thinks of the sentences he uses in thought as grammatically structured. He views them or conceives them as having one or another "deep structure" grammatical analysis. I shall return to this point in a moment. First I note that it is not sufficient for full understanding of an expression that

${ }^{48}$ J. J. Katz and Paul M. Postal, An Integrated Theory of Linguistic Description (Cambridge, Mass.: M.I.T. Press, 1964).

" J. J. Katz, "Recent Issues in Semantic Theory," Foundations of Language, 3(1967):133.
LANGUAGE, THOUGHT, AND COMMUNICATION

one be able to make formal moves with that expression, at best this shows merely that one understands the expression as having a particular grammatical form. One must also be able to give paraphrases and make inference that involve changes in nonlogical and nongrammatical vocabulary. One must be able to see what sentences containing the relevant expression imply, what they are equivalent with, etc.

It is here, of course, that Katz and others have imagined that appeal must be made to meaning, to entailment by virtue of meaning, to equivalence by virtue of meaning, etc. But that is a mistake. The relevant notions of equivalence and of implication are the ordinary ones: equivalence or implication with respect to one's background assumptions, where no distinctions need be made between analytic or synthetic background assumptions. One has an understanding of an expression to the extent that one can paraphrase sentences containing it, can make inferences involving such sentences, etc. It adds nothing to one's understanding if one can distinguish "analytic" equivalence and implications from "synthetic" ones. In fact, most people cannot do so. Only those who have been "indoctrinated" can; and they are not the only ones who understand the language they think in. ${ }^{48}$

Here it might be objected that sentences used in thinking are often ambiguous. How can we account for that - and for a person's ability to understand or interpret a sentence one way at one time and another way at another time? Can we account for it without assuming that he assigns an interpretation or "reading" to the sentence in the way in which Katz suggests? Well, we can and we can't. An expression is ambiguous if a person can sometimes treat it as having one sort of role and at other times treat it as having a different role. Treated one way it admits of paraphrases it does not admit when treated the other way. This difference in paraphrasability represents the difference in interpretation; but recall that paraphrasability is relative to background knowledge and need not permit any analytic-synthetic distinction. ${ }^{49}$

To account for the difference in the ways a person can use an ambiguous expression we must suppose that he does not simply view it as a sequence of words. He views it, or hears it, as having a particular syntactic structure and as containing words in one or another of their pos-

*I I have discussed this issue from a slightly different point of view in "Ouine on Meaning and Existence, I," Review of Metaphysics, 21 (1967-1968):124-151.

Ibid., pp. 150-151. 


\section{Gilbert Harman}

sible senses. Let us consider each of these things in turn.

Syntactically ambiguous sentences may be heard as having either of two (or more) different syntactic structures. They are like the lines on paper which may be seen as a staircase viewed from the back or from the front. Or they are like a group of dots that may be seen as two groups in one way or as two other groups in another way. Or they are like the figure that can be seen either as a duck or as a rabbit. Thus consider, "They are visiting philosophers." We may see or hear this in two different ways, depending on whether we take "are visiting" together or "visiting philosophers" together. We hear the sentence as admitting either of two groups of paraphrases, either "They are philosophers who are visiting," etc. or "They are visiting some philosophers," etc. Similarly, consider "Visiting philosophers can be unpleasant." The difference in interpretation again depends on how we conceive that sentence's grammatical structure, although the difference is not simply a matter of grouping on the surface. It is rather a matter of what transformational theorists refer to as "deep structure." It is a matter of how we conceive the source of "visiting philosophers." It may be heard as coming from "someone visits philosophers" or from "philosophers visit someone." It is true that the average person is quite ignorant of transformational grammar. But that does not mean he fails to hear that sentence as having one or another of the indicated structures. A person can see lines on a page as forming one or another three dimensional structure without knowing any geometry. Therefore I think that in order to account for the way in which a person can deal with ambiguous sentences, we must assume that in some sense he conceives a sentence used in thought as having one or another syntactic structure. As I have already said above, I think that the same conclusion can be reached if we attempt to account for the formal inferences a person can make, even if we ignore ambiguity.

Similarly, in order to account for the way in which a person deals with ambiguous words, we must assume that he distinguishes a word used in one sense from the same word used in another sense. But we can do that without assuming that he makes the distinction by assigning different readings to the word. He may mark the distinction in sentences by a device as simple as a subscript. The inferences and paraphrases that are then permissible depend in general on the subscript
LANGUAGE, THOUGHT, AND COMMUNICATION

selected. ${ }^{50}$ One reason why no more is needed than a subscript is that the relevant sorts of inference and paraphrase are those possible by virtue of background information. Such background information itself must be "stored" as sentences under certain structural descriptions in cluding subscripted words. But a person can understand the expressions he uses without having divided his background information into a part true by "definition" (the dictionary) and another part not true by definition (the encyclopedia).

We think with sentences conceived under particular structural descriptions, where we may count the subscripts that distinguish word senses as part of the structural descriptions. More precisely, so-called propositional attitudes are sentential attitudes, where the relevant sentences are conceived under particular structural descriptions. In understanding what someone else says to us, we must determine the content of his utterance taken literally. It is sufficient that we should attend to the sentence he utters conceived under the relevant structural description. Therefore, usually we must assign a structural description to his words in the sense that we must hear his words as having a particular syntactic structure. That is not to say that we come (even unconsciously) to know that it has a particular structure; and it is certainly not to say that we have knowledge of the principles that relate phonetic representations to structural descriptions. The situation is strictly analogous to other cases of perceiving something as something. We can perceive a series of lines as a particular three-dimensional structure without thinking that it has that structure, indeed without knowing anything about geometrical structure. We can certainly do so without knowing rules that relate two-dimensional figures and three-dimensional structures.

(To say that a speaker of a language must have unconscious knowledge of the grammar of his language is strictly analogous to saying that a person who sees the world in three dimensions must have unconscious knowledge of geometry: To say that a speaker has internalized a generative grammar is like saying a perceiver has internalized a geometry. Perhaps this is sometimes a harmless way of speaking. But one must be careful lest it illegitimately lead one to a compositional theory of meaning or to a rationalist theory of concept formation.)

${ }^{50}$ Cf. Harman, "What an Adequate Grammar Could Do," Foundations of Language, 2(1966):134-136. 


\section{Gilbert Harman}

Sounds reach a person's ears and, after physiological processes we know little about, he perceives or conceives a sentence under a particular structural description. His understanding of that sentence is represented not by his having assigned it a "reading" in Mentalese but rather by his being able to use the sentence under that structural description in his thought. If we like, we may still speak of "decoding" here, in a sense familiar perhaps from information theory. One decodes certain sounds into a sentence plus structural description. Although this point may be partially responsible for Katz's remarks about decoding, it is not exactly what he had in mind. In the present case we have decoding of sound into sentence under structural description. Katz speaks of decoding the phonetic representation of the sentence. He says, you will recall:

The speech sounds that stimulate these organs are then converted into a neural signal from which a phonetic representation equivalent to the one into which the speaker encoded his message is obtained. This representation is decoded into a representation of the same message that the speaker originally chose to convey by the hearer's equivalent system of linguistic rules. ${ }^{51}$

But that is not what usually happens. One does not first perceive the sounds as a sequence of words and then assign a structural description. It is a commonplace of transformation theory that one's understanding of the sentence will partially determine what words he hears. Whatever "decoding" takes place generally translates certain sounds or (perhaps) neural signals directly into a sentence with structural description. Such a "sound-meaning correspondence" is not given simply by the rules of grammar.

I conclude from the above considerations that it is possible to give an account of how people understand sentences that incorporates the insights gained in transformational grammar without leading one to postulate that a speaker knows that sentences have certain structural descriptions, that he knows the rules of grammar, or that he understands sentences by assigning readings to them.

6. Anomaly and Synonymy. Now Katz and Fodor still have one more card up their collective sleeve. They claim that their semantic theory can account for at least two things that it would be difficult to handle in any other way. First they think their theory can show how certain interpretations of a sentence that are grammatically possible are seman-

" Katz, The Philosophy of Language, p. 104; my emphasis.

\section{LANGUAGE, THOUGHT, AND COMMUNICATION}

tically ruled out, so that they can account for a certain amount of disambiguation with their theory. ${ }^{52}$ Second, at least Katz thinks that the theory shows how certain sentences are analytic, others contradictory, and still others synthetic, so that the theory can account for native speakers' intuitive judgments about analyticity, etc. ${ }^{53}$

But there is no such thing as semantic anomaly and no such distinction as the analytic-synthetic distinction. To believe otherwise is to suffer from a lack of imagination. For example, Katz and Fodor argue as follows:

Now let $\mathrm{S}$ be the sentence The paint is silent. English speakers will at once recognize that this sentence is anomalous in some way. For example, they will distinguish it from such sentences as The paint is wet and The paint is yellow by applying to it such epithets as 'odd,' 'peculiar,' and 'bizarre.' . . . Hence, another facet of the semantic ability of the speaker is that of detecting semantic anomalies. ${ }^{54}$

But surely, whatever anomaly there is in the phrase "silent paint" is due to the fact that paints do not emit noise. If some paints did and some did not, "silent paint" would not be anomalous. And that is to say that there is nothing peculiarly semantic about the anomaly. Its anomaly is a result of our general nonlinguistic knowledge of the world.

Again, Katz and Fodor argue that a theory that incorporates only the sort of considerations I have sketched above

will not be able to distinguish the correct sense of seal in One of the oil seals in my car is leaking from such incorrect senses as 'a device bearing a design so made that it can impart an impression' or 'an impression made by such a device' or 'the material upon which the impression is made' or 'an ornamental or commemorative stamp' and so forth, since all of these senses can apply to nominal occurrences of seal. ${ }^{.55}$

But it requires only a little imagination to see that "seal" may have any of these senses, although in ordinary discourse it would be more likely to have the sense the authors have in mind..$^{56}$

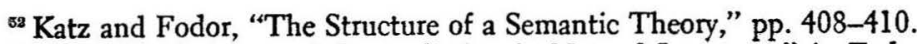

${ }^{53}$ Katz, "Analyticity and Contradiction in Natural Language," in Fodor and Katz, The Structure of Language, pp. 530-541; The Philosophy of Language, pp. 193220; and "Some Remarks on Quine on Analyticity," Journal of Philosophy, 64 (1967):35-52.

${ }^{54}$ Katz and Fodor, "The Structure of a Semantic Theory," pp. 402-403.

Ibid., p. 409

${ }^{5}$ For further discussion of the question whether it is possible to distinguish semantic anomaly or disambiguation from anomaly or disambiguation due to our generally accepted beliefs, see Dwight Bolinger, "The Atomization of Meaning," 


\section{Gilbert Harman}

McCawley has argued a similar point with respect to purported syntactic anomalies of a certain type:

Moreover, it appears incorrect to regard many so-called "selectional violations" as not corresponding to possible messages, since many of them can turn up in reports of dreams:

(2) I dreamed that my toothbrush was pregnant.

(3) I dreamed that I poured my mother into an inkwell.

(4) I dreamed that I was a proton and fell in love with a shapely green-and-orange-striped electron.

or in reports of the beliefs of other persons:

(5) John thinks that electrons are green with orange stripes.

(6) John thinks that his toothbrush is trying to kill him.

(7) John thinks that ideas are physical objects and are green with orange stripes.

or in the speech of psychotics. While one might suggest that a paranoid who says things like

(8) My toothbrush is alive and is trying to kill me.

has different selectional restrictions from a normal person, it is pointless to do so, since the difference in "selectional restriction" will correspond exactly to a difference in beliefs as to one's relationship with inanimate objects; a person who utters sentences such as (8) should be referred to a psychiatric clinic, not to a remedial English course. ${ }^{57}$

I agree and think that supports the view that there is no real distinction between semantic anomaly and anomaly due to "extralinguistic factors."

Similar points apply to Katz's claims about analyticity, etc. First, the fact that people have "intuitions" about analyticity shows at best that there is a distinction between "seems analytic to certain people" and "seems synthetic to them." It does not show that there are sentences that are really analytic as opposed to others that are synthetic. The fact that people once had "intuitions" that some women were witches and others not, certainly fails to show that there were women that really were witches as opposed to others that were not. ${ }^{58}$

Language, 41 (1965):555-573, reprinted in Jakobovits and Miron, Readings in the Psychology of Language, pp. 432-448.

${ }^{87}$ James D. McCawley, "Where Do Noun Phrases Come From?" in R. A. Jacobs and P. S. Rosenbaum, eds., Readings in English Transformational Grammar (Waltham, Mass.: Ginn, 1970), p. 168.

${ }^{58}$ Cf. N. L. Wilson, "Linguistic Butter and Philosophical Parsnips," p. 65; Harman, "Quine on Meaning and Existence, I," pp. 137-138.

\section{I.ANGUAGE, THOUGHT, AND COMMUNICATION}

Second, the intuitive distinction Katz and others make between ana lytic and synthetic truths is easily explained away without appeal to transformational semantic theory: people who have such intuitions suffer from a lack of imagination. The intuitions come from their inability to imagine that certain sentences are false. But as many philosophers have pointed out, after a little practice such things can be imagined. ${ }^{59}$

7. Final remarks. Consider the two views. On the first view, a person who speaks a natural language can think in that language and does not need to translate sentences conceived into some other system of representation, Mentalese. On this view, Mentalese incorporates one's natural language. On the second view, a person cannot think in language and must translate sentences of his language into Mentalese. The incorporation view has the following advantages over the translation view: (1) The incorporation view provides a natural explanation of the way in which learning one's first language makes possible thoughts and other propositional attitudes one would not otherwise have. The translation view must invoke some special principle to account for this. (2) Similarly, the incorporation view suggests an explanation of the way in which unconscious thinking makes use of verbal punning, as revealed in psychoanalytic studies of dreaming, slips of the tongue, and free association. ${ }^{60}$ It is not clear how the translation view could explain such things. (3) The translation view is unnecessarily complicated because it cannot explain anything that is not explicable on the incorporation view. (4) The translation view suggests things that are false about anomaly, synonymy, etc.

Such considerations seem to be the relevant ones to use in deciding which of the two views is more correct. For example, it is difficult to see how neurophysiological evidence could support one of the views against the other (except by pointing to further relatively behavioral phenomena to be explained). For, as descriptions of the mechanism of the brain, the two views must be taken to be descriptions of a fairly

${ }^{5}$ See e.g., Hilary Putnam, "It Ain't Necessarily So," Journal of Philosophy, 59(1962):660; I. M. E. Moravcsic, "The Analytic and the Nonempirical," Journal of Philosophy, 62 (1965):421-423; Harman, "Quine on Meaning and Existence, I." Quine speculates on the mechanism of analyticity "intuitions" in Word and $\mathrm{Ob}$ ject, pp. 56-57, 66-67.

${ }^{\infty}$ I owe this point to Lucy Harman. 


\section{Gilbert Harman}

abstract sort. And it is not easy to see how any neurological mechanism that might account for the relevant behavior and that could be interpreted as an instantiation of one of the descriptions could not also be interpreted as an instantiation of the other. Therefore, I see no reason not to accept the incorporation view. ${ }^{61}$

ar I discuss these issues further in Thought (Princeton, N.J.: Princeton University Press, 1973).

\section{Knowledge of Language}

There are a number of different questions that I would like to touch upon in these lectures, questions that arise at various levels of generality and that grow out of different, though not totally unrelated concerns. I want to present a certain framework within which, I believe, the study of language can be undertaken in a very fruitful way - not the only framework, to be sure, and one better suited to certain problems than to other, equally legitimate ones. Within this framework I would like to discuss some technical questions that are at or near the borders of research. At this level of discussion, I will be presenting some material that is internal to the theory of transformational generative grammar. But I would also like to suggest that this rather technical material is potentially of quite general interest, that by studying it we can hope to learn some important things about the nature of human intelligence and the products of human intelligence, and the specific mechanisms that enable us to acquire knowledge from experience, specific mechanisms that, futhermore, provide a certain structure and organization for and no doubt certain limits and constraints on, human knowledge and systems of belief. I think that the work I will describe at least hints at a concept of man that is rather different, in interesting respects, from others that have been implicit in much modern thinking about these matters, and would like to elaborate on this question as well. I have in mind, then, a large enterprise, of which only a small part can be carried out with a satisfactory degree of clarity and precision. Still, I think it is useful to consider this small part against the background of what might ultimately be achieved.

The study of language, as I will be considering it here, can be regarded as a part of human psychology. It forms a part of the general study

AUthoR's NOTE: This essay is the first of six John Locke Lectures delivered at Oxford University in May-June 1969. Parts appeared in the London Times Literary Supplement, May 15, 1969. The other lectures have not yet been published. 